\title{
ATRAUMATIC GB PERFORATION: APPEARANCE AT USG WITH SURGICAL CORRELATION
}

\author{
Pronami Borah1, Biswajit Borah², Rudra K. Gogoi³, Dhaval D. Dhingani ${ }^{4}$
}

${ }^{1}$ Assistant Professor, Department of Radio-diagnosis, Assam Medical College \& Hospital, Dibrugarh.

${ }^{2}$ Assistant Professor, Department of Surgery, Assam Medical College \& Hospital, Dibrugarh.

${ }^{3}$ Professor, Department of Radio-diagnosis, Assam Medical College \& Hospital, Dibrugarh.

${ }^{4}$ Post Graduate Trainee, Department of Radio-diagnosis, Assam Medical College \& Hospital, Dibrugarh.

\section{ABSTRACT}

\section{BACKGROUND}

Non-traumatic Gallbladder (GB) perforation is a rare and severe complication of acute cholecystitis and cholelithiasis. This entity requires importance, because of associated high morbidity and mortality rates due to delay in diagnosis and treatment, since signs and symptoms of perforation do not differ significantly from those of uncomplicated cholecystitis.[1] We undertook the study to analyze patients diagnosed preoperatively as GB perforation with pericholecystic abscess or biloma formation on USG and confirmed at surgery.

\section{METHODS}

It is an observational study done in patients diagnosed preoperatively during the year 2012-2015, as GB perforation in ultrasound. Findings of Ultrasonography were analyzed and also confirmed at surgery.

\section{RESULTS}

Total thirteen cases of GB perforation were evaluated by USG, out of which the most common type of GB perforation was type II (76.9\%) followed by type III (15.4\%) and type I (7.7\%); $61.5 \%$ of cases showed wall defect in the body of the GB; $92.3 \%$ cases were associated with cholelithiasis.

\section{CONCLUSION}

Ultrasonography (USG) is both sensitive and specific primary imaging modality for the assessment of gall stones, biliary dilatation and in acute inflammatory diseases of the gall bladder including its wall. The gap sign of the GB wall perforation can be well visualized on USG.

\section{KEYWORDS}

GB perforation, Acute Cholecystitis, USG.

HOW TO CITE THIS ARTICLE: Pronami Borah, Biswajit Borah, Rudra K. Gogoi, Dhaval D. Dhingani. "Atraumatic GB Perforation: Appearance at USG with Surgical Correlation." Journal of Evolution of Medical and Dental Sciences 2015; Vol. 4, Issue 96, November 30; Page: 16185-16189, DOI: 10.14260/jemds/2015/2377

\section{INTRODUCTION}

Non-traumatic gallbladder perforation is a rare complication of acute cholecystitis and cholelithiasis. Delay in the diagnosis always carries bad prognosis. It has a reported mortality rate of $12 \%-42 \%{ }^{[2,3]}$ Imaging plays a crucial role in differentiating complicated and uncomplicated acute cholecystitis.,[4,5] as signs and symptoms of perforation do not differ significantly from those of uncomplicated cholecystitis. $[1,6,7]$

\section{METHODS}

It is an observational study done in thirteen (13) patients with Ultrasonographic diagnosis of GB perforation during the year 2012-2015. USG findings were analysed and confirmation of these findings was done at surgery. Neimeier's classification for GB perforation was used for categorizing the patients. The patients were scanned by a 3.5$5 \mathrm{MHz}$ curvilinear probe with full bladder by Siemens Acuson Antares 5 Ultrasound System.

\section{Financial or Other, Competing Interest: None}

Submission 14-11-2015, Peer Review 16-11-2015,

Acceptance 23-11-2015, Published 30-11-2015.

Corresponding Author:

Dr. Pronami Borah,

Assistant Professor,

Department of Radio-diagnosis,

Assam Medical College \& Hospital,

Dibrugarh.

E-mail: pronamiborah@yahoo.in

DOI:10.14260/jemds/2015/2377

\section{RESULTS}

Clinically, most of the patients presented with acute abdomen with features of dyspepsia. Three cases had imaging as well as blood picture of pancreatitis. Out of the total thirteen cases of GB perforation, $10(76.9 \%)$ cases were male and $3(23.1 \%)$ cases were female. All of them were in adult age group. Type II GB perforation accounted for $76.9 \%$ of the cases, $15.4 \%$ cases were of type III and $1(7.7 \%)$ case were of type I. In our study, we came across only one case of type I GB perforation. The patient had biliary helminthiasis, both in the CBD and IHBRs causing complete obstruction of the biliary tree (Fig: G1 and 2); $61.5 \%$ of cases showed defect in the wall, i.e., gap sign (Fig: A, B, C and D white arrow). One case of partially distended GB having air fluid level and pneumobilia (Fig: E red arrow) was seen along with gall stone ileus, where the calculus was in the ileum in CECT abdomen (Fig: E white arrow).

The other case of type III GB perforation showed contracted GB, pneumobilia with an extraluminal calculus. Twelve cases $(92.3 \%)$ were associated with cholelithiasis and one case $(7.7 \%)$ was associated with biliary helminthiasis and sludge; $76.9 \%$ cases calculi were seen within the lumen while extraluminal calculus (Fig: $\mathrm{F}$ white arrow) was seen in two cases. Regarding site of perforation, $61.5 \%$ of cases (8 patients) had perforation in the body of GB (Fig: A, B and D white arrow); $23.1 \%$ cases (3 patients) had perforation in the fundus (Fig: $\mathrm{C}$ white left up arrow) of the GB and in rest 15.4 $\%$ of cases ( 2 patients) the site could not be determined as the GB was in collapsed state and had cholecystoenteric fistula. 
A 53.8\% of cases showed wall thickening and in 58.3\% cases GB were partially distended. Associated debris was seen in $41.7 \%$ of cases, while pericholecystic collection was seen in $83.3 \%$. Liver abscess was seen in $2(15.4 \%)$ cases along with a gap in the wall of GB, which were evaluated by contrast CT scan that showed thick wall enhancing collections suggesting liver abscess. Out of the thirteen cases three patients could not be traced, others undergone open cholecystectomy and GB perforations were confirmed. Cases with type III GB perforation had undergone enterotomy with removal of the stone and primary repair together with cholecystectomy.

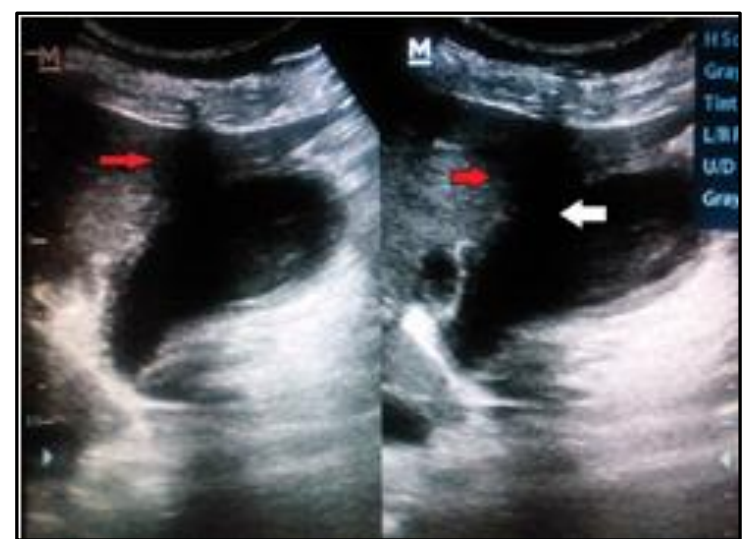

Fig. A:USG image showing Rent in the GB Wall (White Arrow) with a Pericholecystic Collection (Red Arrow)

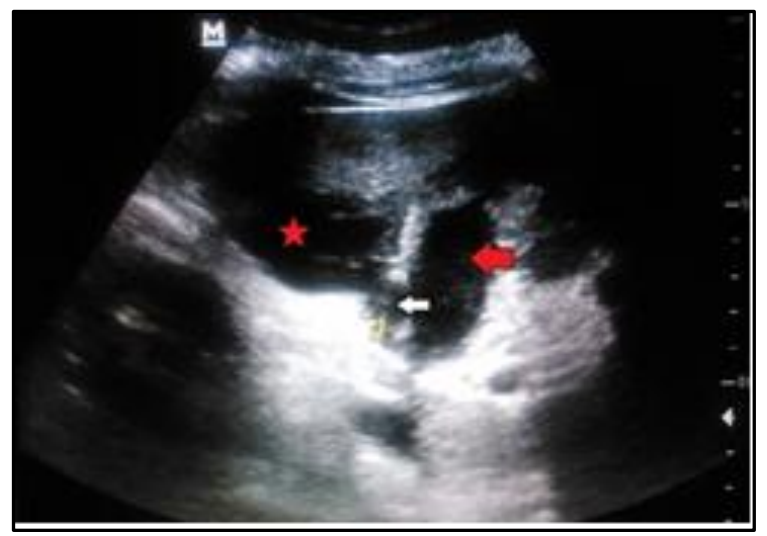

Fig. B: Grey Scale USG image showing the Gall Bladder(Red Arrow) with a Rent in the Wall (White Arrow) and an Intrahepatic Collection (Red Star)

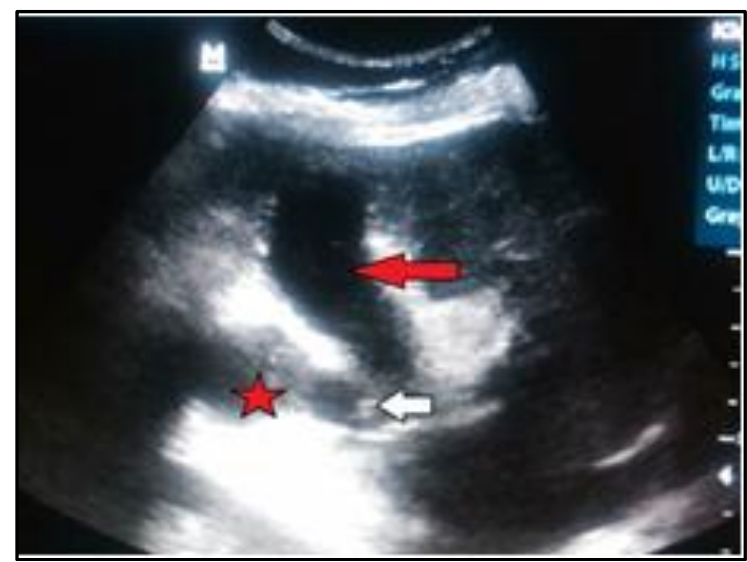

Fig. C:Grey Scale USG image showing the Gall Bladder (Red Arrow) with a Rent in the Fundus (White Left Up Arrow) with an Intrahepatic Collection (White Star)

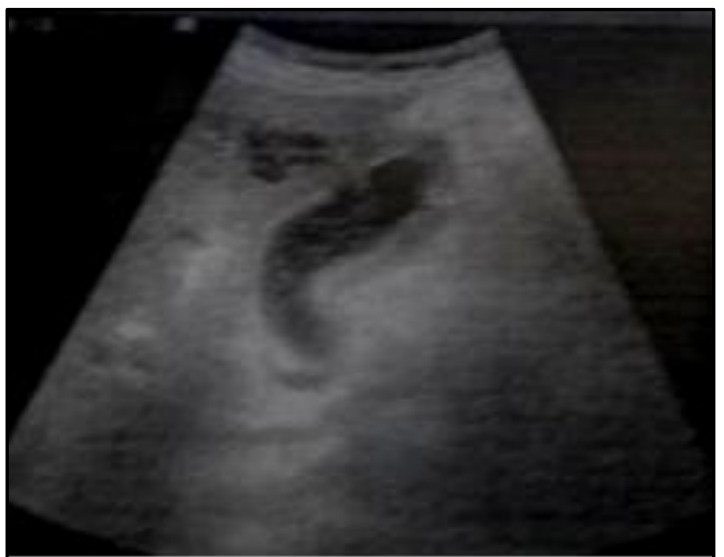

Fig. D: Grey Scale USG image showing the Gall Bladder with a Rent in the Anterior Wall (White Arrow) with an Intrahepatic Abscess (Red Star)

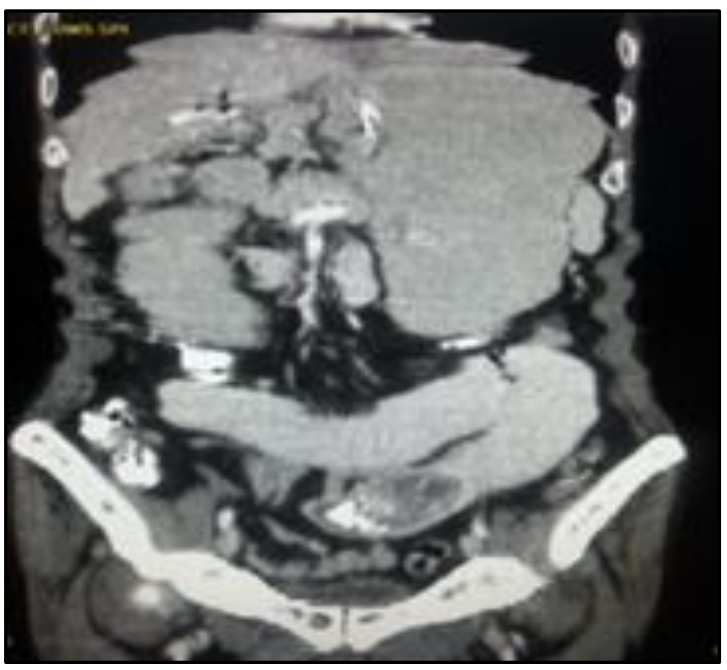

Fig. E: CECT Abdomen showing Pneumobilia (Red Arrow) and Dilated Small Bowel Loops along with a Calculus in a Small Bowel Loop (White Arrow)

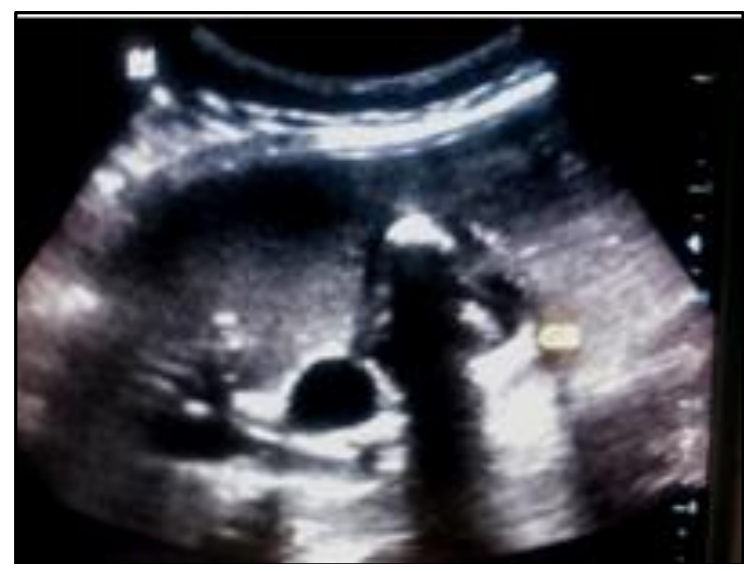

Fig. F: Grey Scale USG image showing Partially Distended GB (Red Arrow), Extraluminal Calculus (White Arrow) and Intrahepatic Collection (Red Star) 


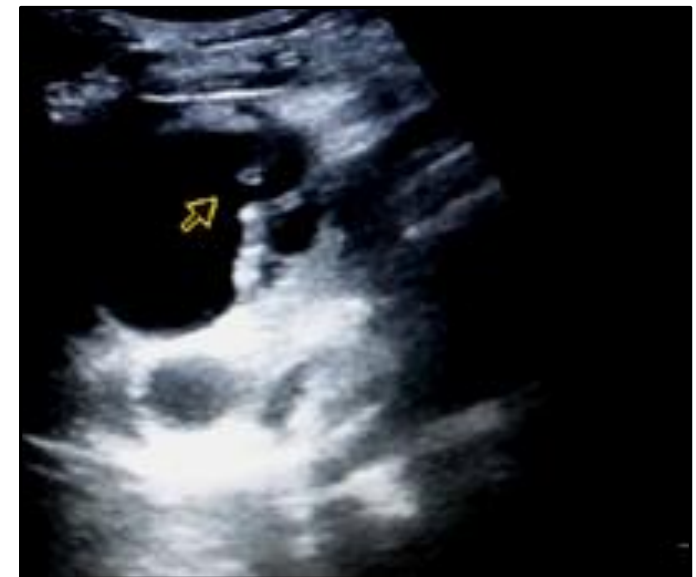

Fig.G1: Grey Scale USG image showing the Gall Bladder with a Rent in the Wall and Pericholecystic Collection (Yellow Arrow) with Worm in the CBD (White Arrow in G1 and 2) and IHBR (Red Arrow in 2) along with Intraperitoneal Free Fluid (White Star)

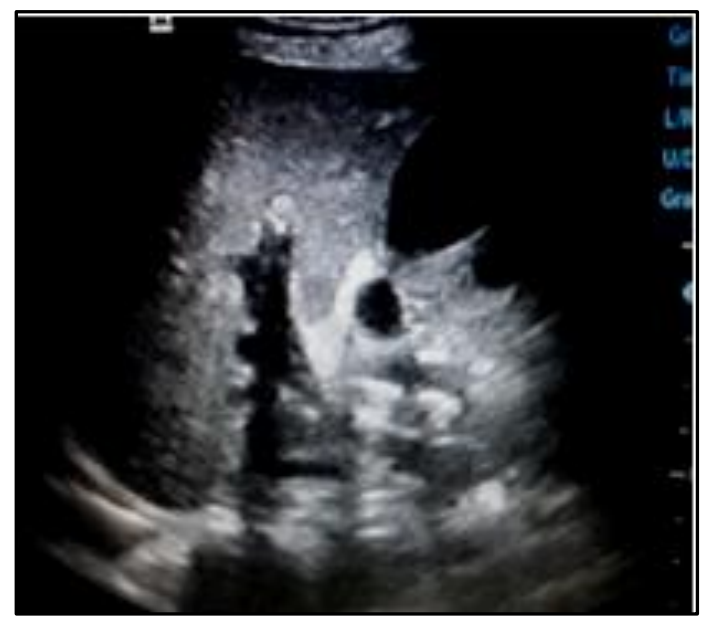

Fig.G2: Grey Scale USG image showing the Gall Bladder with a Rent in the Wall and Pericholecystic Collection (Yellow Arrow) with Worm in the CBD (White Arrow in G 1 and 2) and IHBR (Red Arrow in 2) along with Intraperitoneal Free Fluid (White Star)

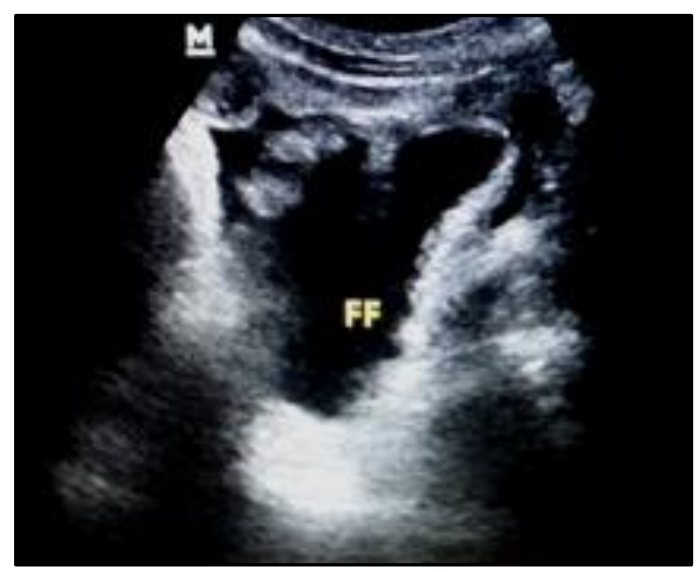

Fig.G3: Grey Scale USG image showing the Gall Bladder with a Rent in the Wall and Pericholecystic Collection (Yellow Arrow) with Worm in the CBD (White Arrow in $G 1$ and 2) and IHBR (Red Arrow in 2) along with Intraperitoneal Free Fluid (White Star)

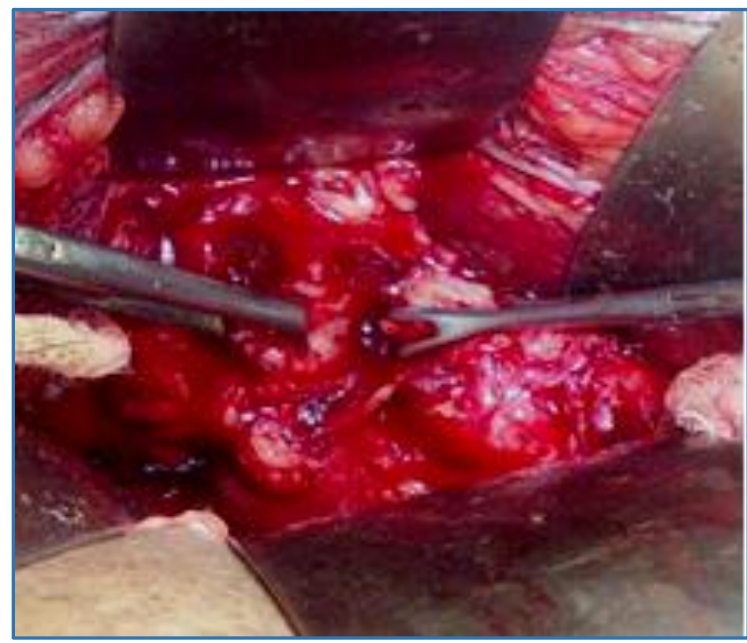

Fig. H: Intraoperative Picture showing Perforated Site of the GB (White Arrow), Duodenum (Blue Arrow) and Liver Surface (Black Arrow)

DISCUSSION: Non-traumatic gallbladder perforation is a rare complication of acute calculus cholecystitis. Onset of perforation varies during the course of acute cholecystitis extending from early in the course to several weeks after the onset. Due to poor blood supply, fundus of the GB is the most common site of perforation. $[1,5,7,8,9]$ Whenever perforation occurs in the isthmus or ducts, omentum and intestines can seal off easily and the condition remains confined to the right upper quadrant with formation of local inflammation and pericholecystic fluid. But if the site of perforation is at the fundus, omentum cannot seal off properly and bile and stones can easily escape into the peritoneal cavity.[1,2,8,10,] In our study, the most common site of perforation was the wall of the body of GB, i.e., $50 \%$ and thus presented with type II GB perforation.

According to Neimeier (1934), GB perforations are classified into three categories: Type I (acute) includes free perforation into the peritoneal cavity with generalized peritonitis, type II (sub-acute) describes localized perforation with pericholecystic abscess and localized peritonitis and type III (chronic) patients with cholecystoenteric fistulas. Less frequent forms include cholecystobiliary fistula and more complex fistula formations. $[2,8,10,11]$ Similar to Derici H. et al. (1), in our study type III GB perforations were presented with chronic cholecystitis and symptoms of intestinal obstruction. Cases of intrahepatic perforation of the GB with liver abscess and cholecystohepatic communication has also been reported. $[3,7,8,12]$

The predisposing factors for GB perforation include cholelithiasis, infection, malignancy, trauma, drugs (Corticosteroids), congenital abnormality, pancreatic secretions, obstruction, calculi and impaired vascular supply. ${ }^{[5,7,12]}$ Elderly patients are very susceptible to GB perforation.[12] Tsai et al.[2] propose to consider GB perforation particularly in patients who are older than 70 years and have a high segmented neutrophil count $>80 \%$.

As there are no classical signs and symptoms of GB perforation clinically, it is difficult to differentiate between patients with perforated GB and those with uncomplicated acute cholecystitis. A sudden decrease in intensity of pain, caused by relief of high intracholecystic pressure might herald the perforation according to Ethan et al. and Chen et al.[5,13] Gore et al.[14] suggest that perforation and abscess formation should be suspected in those patients with acute cholecystitis who suddenly become toxic and clinical condition deteriorate rapidly. Complications that might follow GB perforation are pneumoperitoneum, bile leakage, liver GB 
fossa or intraperitoneal abscess formation and small bowel obstruction.[14]

USG, CECT and MRI are the important imaging modalities for preoperative diagnosis of this rare complication of acute cholecystitis to prevent increase mortality and morbidity. Out of these USG is the initial investigation modality when acute cholecystitis is suspected. $[4,7,8,15]$ Sonographic appearances of GB perforation are diverse and nonspecific. It will show signs of acute cholecystitis like wall thickening $(>3 \mathrm{~mm})$, distension (largest diameter $>3.5-4 \mathrm{~cm}$ ), gall stones, coarse intracholecystic echogenic debris and bile duct dilatation and gap or 'hole sign' in the GB wall.[5,14,15,16,] Another specific sign of GB perforation is the visualization of extraluminal gall bladder calculus.

Sometimes USG features are non-specific like collapsed GB lumen, pericholecystic fluid and pericholecystic abscess. [5] Distension of the GB and edema of its wall may be the earliest detectable signs of imminent perforation.[16] Sood et al.[16] noted that the "sonographic hole sign," in which the defect in $\mathrm{GB}$ wall is visualized is the only reliable sign of GB perforation as seen in $83.3 \%$ of cases in our study.

An intrahepatic perforation is suggested by the presence of a liver abscess with direct continuity into the GB or containing echogenic calculus in the absence of a pericholecystic abscess. Also the impossibility to visualize GB in the presence of a Liver abscess is highly suggestive of an intrahepatic perforation. ${ }^{[7,14]}$ According to Singal et al..[7] type I GB perforation is difficult to diagnose.

USG is helpful only in preoperative evaluation by depicting presence of free fluid and USG guided tapping which will show presence of bile in it. Although ultrasound remains the preferred initial examination for evaluation of suspected GB perforation, but presence of excessive gas in the bowel loops and intense pain associated with this condition decreases the efficacy of this imaging modality. [8] USG findings in our patients were same as that of the referred studies of GB perforation like presence of hole in the GB wall, pericholecystic collection and GB wall edema.

Cases where USG is inclusive we have to go for CECT or MRI. CECT will help in the settings of emphysematous cholecystitis and GB perforation. [7,5] According to Chiapponi et al.,[8] CECT findings can be divided into primary gallbladder changes, pericholecystic changes and findings of extra GB organs. Wall thickening, enhancement and defect, intramural abscess, gas and hemorrhage, calculus in GB, CBD or cystic duct along with intraluminal membrane and gas are the primary gallbladder changes.

Pericholecystic fat stranding and fluid collection, abscess and biloma formation and extraluminal calculus are the pericholecystic changes. Enhancement of the pericholecystic liver, liver abscess, portal vein thrombosis, reactive mural thickening of adjacent bowel loops, regional lymph nodes, intraperitoneal free air, ascites, ileus and Mirizzi syndrome are the findings in the organ other than gall bladder. ${ }^{[6,8]}$ According to M. Karcaaltincaba et al.[17] because of superior contrast resolution and multiplanner imaging MRCP is superior in detecting calculus in the bile ducts, biliary dilatation and the connection of a pericholecystic fluid to the GB as well as abdominal wall.

Condition that may simulate GB on sonogram include ascites, pancreatitis and peritonitis.[16] Scans of the GB bed in upright or decubitus position may displace free fluid from the GB region. Extrapancreatic fluid collection secondary to pancreatitis may accumulate in the anterior pararenal space and usually do so on the left side.[16] However, if accumulation occurs in the right pararenal space it could mimic a pericholecystic process on sonography. Peritonitis leads to an inflammatory response by the peritoneum with development of fibrous strands.

According to Maingot's abdominal operation.,[18] treatment of type I gallbladder perforation is early cholecystectomy; in type II GB perforations managements include drainage of the abscess and cholecystectomy which can be performed at the same time or may be staged depending on the size of the collection and specific patient circumstances and in type III enterotomy is to be done after milking the stone retrogradely. As in most of the cases of type III GB perforation the GB disease is not in acute state so the procedure of choice depends upon the condition of the patient.

\section{CONCLUSION}

There are no known classical signs and symptoms of GB perforation, so it is difficult to differentiate clinically between patients with perforated GB and those with uncomplicated acute cholecystitis. Ultrasonography (USG) is the primary imaging modality for the assessment of patients with suspected GB and/or biliary system pathology. USG is both sensitive as well as specific in demonstration of biliary diseases. Occasionally, additional imaging modalities are indicated in complicated biliary disease where USG findings are inconclusive and for identifying ductal anatomical variations when more detailed diagnostic information is required for treatment planning. Early detection of this rare but lethal complication will decrease both mortality and morbidity of patients.

\section{REFERENCES}

1. Derici H, Kara C, Bozdag AD, Nazil O, Tansug T, Akca E: Diagnosis \& treatment of gall bladder perforation. World J Gastroenterol 2006;12:7832-7836.

2. Tsai MJ, Chen JD, Tiu CM et al. Can acute cholecystitis with gall bladder perforation be detected preoperatively by computed tomography in ED? Correlation with clinical data \& computed tomography features. Am J Emerg Med 2009;27:574-81.

3. Date RS, Thrumurthy SG, Whiteside S, et al. Gallbladder perforation: case series \& systematic review. Int J Surg 2012;10:63-8.

4. Siegelman SS, Copeland BE, Saba GP, Cameron JL, Sanders RC, Zerhouni EA. CT of fluid collections associated with pancreatitis. AJR Am J Roentgenol 1980 Jun ;134(6):1121-32.

5. Ethan A. Smith, Jonathan R. Dillman, Khaled M. Elsayes, Christine 0, Menias, Ronald O. Bude. Cross- sectional Imaging of Acute \& Chronic Gall Bladder Inflammatory Disease AJR 2009;192:188-196.

6. Kochar K, Vallance K, Mathew G, Jadhav V. Intrahepatic perforation of the gall bladder presenting as liver abscess: Case report, review of literature \& Niemeier's classification.

Eur J GastroenterolHepatol 2008;20:240-244.

7. Singal R, Gupta S, Singal RP, Mittal A, Sharma S, et al. Gall bladder perforation leads to Liver Abscess formation Role of Ultrasonography. J Gastrointest Dig Syst 2015; 5:279.doi :10.4172/2161 -069X.1000279.

8. Costanza Chiapponi, Stephan Wirth \& Matthias Siebeck. Acute Gall bladder perforation with gallstones spillage in a cirrhotic patient. World Journal of Emergency Surgery 2010;5:11.

9. Neel B Patel, Aytekin Oto, Stephen Thomas. Multidetector CT of Emergent Biliary Pathologic conditions. Radiographics 2013;33:1867-1888.

10. Anderson BB, Nazem A: Perforations of the gall bladder \& cholecystobilliary fistula: a review of management \& a new classification. J Natl med Assoc 1987;79:393-399. 
11. Niemeier DW. Acute free perforation of the gall bladder. Ann Surg 1934;99:922-4.

12. Bakalakos EA, Melvin WS, Kirkpatrick R: Liver abscess secondary to intrahepatic perforation of the gall bladder, presenting as a Liver mass. Am J Gastroenterol 1996;91:1644-1646.

13. Chen JJ, Lin HH, Chiu CT, Lin DV: Gall bladder perforation with intrahepatic abscess formation. J clin Ultrasound 1990;18:43-45.

14. Gore RM, Ghahremani GG, Joseph AE, Nemcek AA Jr., Marn CS, Vogelzang RL: Acquired malposition of the colon \& Gall bladder in patients with Cirrhosis: CT findings \& clinical implications. Radiology 1989;171:739-742.
15. Rumack CM, Wilson SR, Charboneau JW, Johnson JA. Diagnostic ultrasound, 3rd ed. vol.1. St. Louis, MO: Elsevier Mosby 2005;197-201.

16. Sood BP, Kalra N, Gupta S, et al. Role of sonography in the diagnosis of Gall bladder perforation. J Clin Ultrasound 2002;30:270-4.

17. M Karcaaltincaba, Mark D, Hohenwaltera, Scott J. Erickson, Andrew J. Taylor. MRCP findings of Gall bladder perforation and pericholecystic abscess. CIMG Extra: Cases 28 (2004) 59-61.

18. Maingot's Abdominal operations 10th edition, vol. IIpg 1736. 